\title{
CES
}

COOPERATIVISMO E ECONOMÍA SOCIAL

Núm. 41 (2018-2019), páxs. 241-245

ISSN: $1130-2682$

\section{EL REEMBOLSO DE LA PRIMA DEL SEGURO DE CAUCIÓN EN LAS COOPERATIVAS DE VIVIENDAS}

\section{THE REFUND OF SURETY INSURANCE PRIME IN THE FIELD OF HOUSING COOPERATIVES}

\author{
Sinesio Novo FernándeZ*
}

Letrado de la Administración de Justicia del Juzgado de lo Social nº 2 de Lugo. Dirección de correo electrónico: sinenovo@yahoo.es. 



\section{RESUMEN}

$\mathrm{E}$ 113 de septiembre de 2013 se produce la baja voluntaria de Dña. Carlota en la entidad "El prado de Valdebebas Sociedad Cooperativa". Dicha baja fue calificada como justificada y la antigua socia formuló demanda contra la entidad para reclamar el reintegro de las aportaciones que había efecutado. La parte demandada se allana parcialmente, reduciéndose el objeto de la litis a determinar el carácter reembolsable de la póliza de seguro de caución concertado para garantizar la devolución de las cantidades aportadas por la cooperativista en caso de que no se iniciase la construcción de las viviendas, éstas no llegasen a buen fin o no se entregasen en los plazos convenidos. La sentencia de primera instancia condena a la cooperativa al pago de todas las cantidades reclamadas, por lo que la demandada interpone el correspondiente recurso frente a esta resolución. La alzada se fundamente en tres alegaciones. En primer lugar, la recurrente manifiesta falta de legitimación pasiva, al tratarse de un seguro concertado por la demandante con la aseguradora. La cooperativa actuó únicamente como mediadora, limitándose a recibir el dinero de la cooperativista para entregarlo a la compañía. En segundo término, el recurso se fundamente en que la póliza no es un concepto reembolsable por no integrar el capital ni corresponder a cantidades dirigidas a financiar la construcción de las viviendas. Finalmente, la apelante expone que no ha transcurrido el plazo de cinco años fijado legal y estatutariamente para devolver las aportaciones en caso de baja justificada.

La sentencia de apelación no estima ninguno de los motivos alegados en torno al reembolso de la prima de seguro de caución. Respecto a la primera alegación, de falta de legitimación pasiva de la cooperativa, dice el tribunal que, como consta en los propios certificados individuales de seguro aportados en la contestación a la demanda, es la cooperativa la que, como tomadora del seguro, suscribe la correspondiente póliza colectiva y, como tal, le corresponde la obligación del pago de la prima a la aseguradora. Los cooperativistas no tienen relación contractual con la aseguradora, sin perjuicio de su condición de asegurados a cuyo favor se emiten las correspondientes pólizas individuales.

En cuanto al carácter reembolsable de la prima, entiende la sentencia de apelación que la cantidad abonada por la demandante en concepto de seguro de caución debe serle reintegrada, en tanto que se trata de una aportación que sufraga los gastos generales de la cooperativa y, como tales, se encuentran incluidos en el precio de la vivienda. Así las cosas, la prima de seguro es una cantidad satisfecha por la cooperativista para la financiación del inmueble sin que su reembolso esté excluido legal o estatutariamente. 
Respecto al transcurso del plazo de cinco años desde la fecha de la baja para que el cooperativista exija el reembolso, argumenta la Audiencia Provincial que la cuestión no fue alegada en la contestación a la demanda. En cualquier caso, el mencionado plazo decaería desde el momento en que el cooperativista fue sustituido por otro con anterioridad a la interposición de la demanda.

\section{Anotación}

La primera de las cuestiones debatidas, que versa sobre la legitimación pasiva de la cooperativa, no puede escindirse del fondo del asunto, como bien dice el tribunal de apelación, esto es, no puede analizarse con independencia de la decisión acerca del carácter (reembolsable o no) de la prima de seguro. La característica de reembolsable supone el derecho que tiene el socio que causa baja a que la cooperativa le devuelva la partida en cuestión. Por lo tanto, si se llega a la conclusión de que dicha partida es reembolsable, es la cooperativa la obligada a reintegrársela al socio y la legitimada pasivamente para su reclamación. En cualquier caso, para analizar la cuestión de fondo de la sentencia que nos ocupa, es imprescindible el estudio del llamado seguro de caución. A partir de la regulación contenida en el artículo 68 de la Ley de Contrato de Seguro, en la Ley 57/68 de 27 de julio, reguladora de las percepciones de cantidades anticipadas en la construcción y venta de viviendas y en la Orden de 29 de noviembre de 1968, de Seguro de Afianzamiento y de Cantidades Anticipadas, podemos establecer que estamos ante un seguro obligatorio por el que la compañía aseguradora se obliga, en caso del incumplimiento por la promotora de sus obligaciones legales o contractuales, a devolver al asegurado las cantidades entregadas a cuenta. Así las cosas, en virtud de la legislación enumerada, aparece el promotor como tomador del seguro de caución. Podemos definirlo como aquella persona física o jurídica que contrata el seguro por el posible incumplimiento en sus obligaciones. En el supuesto de las cooperativas objeto de análisis, esto es, asociaciones de personas que promueve la construcción de viviendas, estamos ante una promoción colectiva por parte de los socios en la que la persona jurídica ocupa una posición de promotora mediadora (TATO PLAZA, A., "As cooperativas de vivendas e a condición de promotor", As cooperativas de Vivendas no Marco da Lei 5/1998 de Cooperativas de Galicia, Santiago de Compostela, Centro de Estudios Cooperativos, 2007, p.71). Otro de los elementos que intervienen en el seguro de caución es el asegurado, o persona física o jurídica que entrega unas cantidades a cuenta para la adquisición de un inmueble en construcción. Cada uno de los socios de una cooperativa de viviendas serían los asegurados en esta modalidad contractual. Como tercer elemento personal aparece el asegurador, esto es, la compañía de seguros que se compromete a la devolución de las cantidades entregadas a cuenta en caso del incumplimiento del promotor. Siguiendo con la regulación del seguro de caución, en el mismo han de emitirse dos tipos de documentos: el contrato de seguro colectivo, que en el caso 
que nos ocupa es el que se celebra entre el asegurador y la cooperativa; y la póliza individual de seguro complementaria, firmada entre el asegurador y cada uno de los asegurados, en la que se determina la cantidad aportada por el adquirente y que por tanto resulta cubierta por la póliza en caso de producirse el siniestro.

En otro orden de cosas, la naturaleza reembolsable de la prima del seguro de caución se predica de la literalidad del artículo 89.5 de la Ley 27/1999, de 16 de julio, de Cooperativas, en virtud del cual "los Estatutos podrán prever en qué casos la baja de un socio es justificada y para los restantes, la aplicación, en la devolución de las cantidades entregadas por el mismo para financiar el pago de las viviendas y locales, de las deducciones a que se refiere el apartado 3 del artículo 51, hasta un máximo del 50 por 100 de los porcentajes que en el mismo se establecen.

Las cantidades a que se refiere el párrafo anterior, así como las aportaciones del socio al capital social, deberán reembolsarse a éste en el momento en que sea sustituido en sus derechos y obligaciones por otro socio".

En el precepto se observa que serán objeto de reembolso no solo las aportaciones al capital social, sino todas las cantidades entregadas por el socio para financiar el pago de las viviendas. Teniendo en cuenta el carácter preceptivo del seguro de caución en este tipo de actividad, es innegable la inclusión de la prima como concepto necesario para la construcción de las viviendas y, en consecuencia, su carácter reembolsable.

Finalmente, respecto al plazo del que dispone una cooperativa para el reembolso de las cantidades debidas al socio que causa baja, el artículo 89.5 de la Ley 27/1999, de 16 de julio, de Cooperativas, no deja lugar a la interpretación, en el sentido de que obliga al reembolso en el momento en que el socio que causa baja sea sustituido en sus derechos y obligaciones por otro. Siguiendo lo manifestado por la Audiencia Provincial de Madrid, la aplicación de la ley anterior en vez de la ley de Cooperativas de la Comunidad de Madrid, se justifica por el carácter estatal de la sociedad demandada. En cualquier caso, el contenido del artículo 114.5 de dicha norma se identifica plenamente con el mencionado precepto de la Ley 27/1999. 